\title{
Giant crystals inside mitochondria of equine chondrocytes
}

\author{
S. Nürnberger ${ }^{1,2,3,4} \cdot$ C. Rentenberger ${ }^{5} \cdot$ K. Thiel $^{6} \cdot$ B. Schädl ${ }^{2,3,4} \cdot$ I. Grunwald $^{6}$

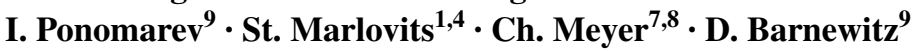

Accepted: 9 November 2016 / Published online: 24 December 2016

(C) The Author(s) 2016. This article is published with open access at Springerlink.com

\begin{abstract}
The present study reports for the first time the presence of giant crystals in mitochondria of equine chondrocytes. These structures show dark contrast in TEM images as well as a granular substructure of regularly aligned 1-2 nm small units. Different zone axes of the crystalline structure were analysed by means of Fourier transformation of lattice-resolution TEM images proving the crystalline nature of the structure. Elemental analysis reveals a high content of nitrogen referring to protein. The outer shape of the crystals is geometrical with an up to hexagonal profile in cross sections. It is elongated, spanning a length of several micrometres through the whole cell. In some chondrocytes, several crystals were found, sometimes combined in a single mitochondrion. Crystals were preferentially aligned along the long axis of the cells, thus appearing in the same orientation as the chondrocytes in the tissue. Although no similar structures have been found in the cartilage of any
\end{abstract}

Electronic supplementary material The online version of this article (doi:10.1007/s00418-016-1516-6) contains supplementary material, which is available to authorized users.

S. Nürnberger

sylvia.nuernberger@meduniwien.ac.at

1 Department of Trauma Surgery, Medical University of Vienna, Waehringer Guertel 18-20, 1090 Vienna, Austria

2 Ludwig Boltzmann Institute for Experimental and Clinical Traumatology, AUVA Research Center, Donaueschingenstrasse 13, 1200 Vienna, Austria

3 University Clinic of Dentistry, Medical University of Vienna, Sensengasse 2a, 1090 Vienna, Austria

4 Austrian Cluster for Tissue Regeneration, Vienna, Austria

5 Physics of Nanostructured Materials, Faculty of Physics, University of Vienna, Boltzmanngasse 5, 1090 Vienna, Austria other species investigated, they have been found in cartilage repair tissue formed within a mechanically stimulated equine chondrocyte construct. Crystals were mainly located in superficial regions of cartilage, especially in joint regions of well-developed superficial layers, more often in yearlings than in adult horses. These results indicate that intramitochondrial crystals are related to the high mechanical stress in the horse joint and potentially also to the increased metabolic activity of immature individuals.

Keywords Cartilage $\cdot$ Protein crystals $\cdot$ Mitochondria Chondrocytes $\cdot$ Histochemistry $\cdot$ Transmission electron microscopy

\section{Introduction}

Protein crystals are dense aggregations of macromolecular protein units which either form a periodic inner substructure or have a geometric shape, or both. In electron optic

6 Department of Adhesive Bonding Technology and Surfaces, Fraunhofer Institute for Manufacturing Technology and Advanced Materials, Wiener Strasse 12, 28359 Bremen, Germany

7 Clinic and Polyclinic for Traumatology, University of Giessen, Rudolf-Buchheim-Straße 7, 35385 Giessen, Germany

8 Orthopaedic and Trauma Surgery, Klinikum Saarbrücken, Winterberg 1, 66119 Saarbrücken, Germany

9 Research Centre for Medical Technics and Biotechnology, Geranienweg 7, 99947 Bad Langensalza, Germany 
images, protein crystals appear evenly electron dense, with either a grid or a dot structure or regularly arranged lines, ladders or helices, and sometimes they have sharp straight borders. At cellular level, they are well known from the granule in mature eosinophil immune cells (Acharya and Ackerman 2014), and they have also been described in several further cell types from prokaryotes to eukaryotes, including bacteria (Bechtel and Bulla 1976), yeast (Veenhuis et al. 2003), invertebrates (Pabst et al. 2006), vertebrates (Djaldetti and Feller 1978; Nagano and Otsuki 1971; Ward 1962) and plants (Moura et al. 2010).

Protein crystals function as storage structures in highly metabolic active tissues such as specialized secretory cells (Santos 1966), hormone-dependent cells (Hawkes 1993; Mesa et al. 2015) or toxin-producing cells (Bechtel and Bulla 1976). They also function under conditions of reduced metabolism and starvation (Ericsson et al. 1966; Hamilton et al. 1966). Further, they are found under pathologic conditions, for instance in cancer (Dogan et al. 2012) or ischaemia (Hanzlikova and Schiaffino 1977). Crystals have been described in almost all parts of the cell: in metabolic active cell compartments as the endoplasmic reticulum (Hasegawa et al. 2011; Jones et al. 1999; Koopmann et al. 2012), secretory vesicles (Santos 1966) and the cytoplasm (Kozina et al. 2011; Schonherr et al. 2015) but also at sites of degradation, the lysosomes (Tsutsui et al. 2015). Additionally, crystals may appear in mitochondria (Farrants et al. 1988), peroxisomes (Schonherr et al. 2015) and the nucleus (Gouranton and Thomas 1974). Typically, a specific crystal type is found in a specific subcellular compartment and is not ubiquitously distributed within the cell, although there are some exceptions (Jain et al. 2001). The protein components may, however, derive from other cell compartments and be transported to the site of crystallization, as it has been observed in the midgut of beetles, where proteins were synthesized in the cytoplasm and transported into the nucleus, where crystals are formed (Gouranton and Thomas 1974).

Little is known about the composition and function of crystals formed in several environments, since the exact identification of the proteins requires the isolation of a certain amount of material, which appears to be difficult in terms of techniques, quantity and frequency. Many crystals are very small, rare or unpredictable in their frequency; some even appear as single observations (Klepal et al. 2010; Silvestro and Chapman 2004). There are, however, examples of adequate descriptions of crystals in bacteria, in cases with less challenging methodological conditions (Sawaya et al. 2014) or in which crystals could be artificially induced, for example via genetic manipulation (Sawaya et al. 2014; Schonherr et al. 2015; Thamwiriyasati et al. 2010; Tsutsui et al. 2015) or by means of free-electron laser and serial femtosecond crystallography (Sawaya et al. 2014).
The best characterized crystals in vertebrates are the granule in mature eosinophil immune cells (Acharya and Ackerman 2014) and Reinke's crystals in testes, which were first described in 1896, mainly in Leydig cells (Reinke 1896). Several studies have confirmed that Reinke's crystals are composed of steroidogenic enzymes and appear only in mature testes and testosterone-producing men, mainly in cryptorchid patients (Kozina et al. 2011). The suggested differences between tumour and non-tumour could, however, not be confirmed. The lack of Reinke's crystals in some studies has been methodologically induced, since they degrade during water-based formalin fixation and require fixation in absolute alcohol to be preserved (Mesa et al. 2015).

In the present study, crystals were found in formalinand glutaraldehyde-fixed samples in giant mitochondria of chondrocytes. They were extensively analysed with different morphological methods such as transmission electron microscopy, element and Fourier transform analysis and histochemical staining. Even though the chemical composition is not yet clarified, the identification of crystal localization has led to hypothesize a relationship between crystal development and mechanical stress conditions.

\section{Materials and methods}

\section{Sample generation}

The main part of this study was performed on native articular cartilage control samples from a horse study and the native cartilage surrounding of an experimentally treated cartilage area. The study was on cartilage defect treatment of experimental full thickness defects of $1.5 \times 2.0 \mathrm{~cm}$ set in the trochlear ridge of the distal femur without damaging the subchondral bone. Defects were treated with four different biodegradable biomaterials seeded with autologous cells gained eight weeks before from the talocrural joint (Nürnberger et al. 2013a) and further with a scaffold-free transplant produced in vitro under mechanical stimulation (Ponomarev and Wilke 2004). Five yearlings were treated in a pilot study with cell-loaded Hyalograft ${ }^{\circledR}$ (Fidia, Italy), Bio-Gide ${ }^{\circledR}$ (Geistlich, Germany) biomaterials and the scaffold-free construct. Study time was three months. Nineteen adult mare horses were transplanted with cell-loaded Hya$\operatorname{lograft}^{\circledR}$, Geistlich ${ }^{\circledR}$ and CaRes ${ }^{\circledR}$ (Arthro-Kinetics, Austria) biomaterials and the scaffold-free construct. The endpoint of the study was one year after implantation. After surgery, the horses stayed two weeks in boxes, were then exercised (walking) and kept thereafter at paddocks. The horses used for this study were healthy Haflingers that did not meet breeding criteria. The study was verified and approved 
by the local ethical board (Thüringer Landesamt für Lebensmittelsicherheit und Verbraucherschutz Nr. 14-03/03, Germany).

Further samples of equine articular cartilage of one adult and two juvenile horse (1 year and 3 months) from different breeders and races and hoof cartilage of 6 adult and one juvenile horse, harvested according to the rules of good scientific practice and approved by the ethical committee, were kindly provided from the University of Veterinary Medicine, Vienna. Sections of articular and epiphyseal cartilage of other species (articular cartilage of rat, chicken, sheep, calf; metaphyseal cartilage of rat and pig) were kindly provided from collaborating laboratories (Ludwig Boltzmann Institute for Experimental and Clinical Traumatology, Vienna, Austria). Human cartilages from femoral heads after femoral head fracture, taken from intact non-arthritic areas, were available in our laboratory from previous investigation (Nürnberger et al. 2006b). Juvenile human cartilage harvested after surgical extraction of supernumerary fingers of polydactyly patients was provided from the Department of Orthopaedics, Medical University of Vienna. Informed consent was obtained from all individual participants included in the study.

\section{Sample preparation and fixation}

Articular cartilage from the horse was fixed either for histology or for electron microscopy. Histological samples were immersed in $7.5 \%$ buffered formaldehyde, rinsed, dehydrated and embedded in paraffin. Sections of $4 \mu \mathrm{m}$ were performed with a microtome (HM355S Micros, Austria). For ultrastructure, samples were fixed in $2.5 \%$ glutaraldehyde in $0.05 \mathrm{M}$ sodium cacodylate ( $\mathrm{pH}$ 7.3). Samples were then postfixed with $0.5 \%$ osmium tetroxide containing $1 \%$ potassium ferrocyanide and dehydrated in a graded series of alcohol and embedded in Agar 100 or low viscosity resin. Semithin sections $(1 \mu \mathrm{m})$ were cut with an ultramicrotome (UC7 Leica Microsystems, Austria), stained with toluidine blue and imaged with an E800 Nikon laboratory microscope.

\section{Transmission electron microscopy (TEM)}

Ultrathin sections $(70 \mathrm{~nm})$ of resin blocks were contrasted with uranyl acetate and lead citrate and imaged with a Zeiss 902 (Oberkochen, Germany) or FEI Morgagni (Hillsboro, USA) electron microscope. To further characterize the crystal composition, TEM measurements were carried out using a FEI Tecnai F20 S-TWIN microscope (Hillsboro, USA) equipped with a GATAN imaging filter (GIF2001). The microscope was operated at an accelerating voltage of $200 \mathrm{kV}$ with a field-emission gun (FEG) resulting in a point resolution of $2.4 \AA$.
The TEM and energy-filtered images were recorded with the slow-scan CCD camera integrated in the GIF $(1024 \times 1024$ pixel array). No binning was used for the TEM images, while for the energy-filtered images a binning of $2 \times 2$ was applied, so that images with a size of $512 \times 512$ pixels were generated. Element maps were recorded using the three-window method; drift between successive images was corrected by a cross-correlation algorithm (Hofer et al. 1997).

For the analysis of crystal morphology and structure a Philips CM200 transmission electron microscope (Eindhoven, Netherlands) was used at an accelerating voltage of $200 \mathrm{kV}$ equipped with a Gatan ${ }^{\mathrm{TM}}$ Orius CCD camera. Different zone axes of the crystalline structure were obtained by tilting using a Philips double tilt sample holder. The analysis of the crystalline lattice and their structural parameters was carried out by fast Fourier transformation (FFT) of the lattice-resolution images.

\section{Histochemistry}

Different histochemical methods were applied in order to find out whether crystals stain in paraffin sections. First, the unspecific toluidine blue staining was used as for resin sections (0.1\% in 2.5\% Borax pH 9) (Pease 1964). Then, protocols were tested with various dyes and affinity to acid structures such as nuclei (Movat, Masson, AZAN, HE), basic proteins (Biebrich Scarlet), carboxylated glycosaminoglycans (Alcian blue, Safranin O) or polysaccharides (PAS). Further, special stainings for specific structures such as amyloids (Congo red), bacteria (GRAM), granulocyte granule (Giemsa) and birefringent structures (Picro Sirius Red) were performed.

Movat is a pentachrom staining (12016 Morphisto/ Sanova), and Masson Goldner (100485 Merck) a trichrome staining, both with acid fuchsin as cell and nuclei stain. The latter was adapted according to Kozina et al. (2011) by extended acid fuchsin and reduced light green incubation time. Heidenhain's AZAN was used with the nucleus stain azo carmine (Kiernan 1999) and MartiusScarlet-Blue (MSB) with Brilliant crystal scarlet apart from Martius Yellow and Methylene blue (Bancroft and Gamble 2008). Hematoxylin and eosin stain (HE) was performed according to the laboratory standard. Periodic acid-Schiff (PAS) (Romeis 1989) is based on basic fuchsin staining (X900 Roth) after oxidative reaction (HP00 Roth). Alcian blue was used as glycosaminoglycan stains to stain carboxylated glycosaminoglycans at $\mathrm{pH} 2.5$ (Romeis 1989) and Safranin O as general glycosaminoglycans stain based on saffron with fast green counterstain. Biebrich Scarlet $(0.04 \%)$ was prepared according to the original protocol (Spicer and Lillie 1961) using Laskey's glycine buffer at pH 8.0 and pH 10.0, Gram staining 
with Carbol-Gentianaviolet solution and Carbol Fuchsin (HP02.1 Roth) and Giemsa (Sigma Aldrich, GS500). Congo red (101340 Merck) and Picro Sirius Red (Whittaker 1995) were analysed under the polarization microscope giving a colour shift to green or green to orange and red, respectively.

Overview sections were scanned with an Olympus BX50 and dotSlide 2.5 software (Olympus) and higher magnifications were imaged with an E800 Nikon research microscope and a NIS Elements software (BR 4.20.00). Manual Z-stacks were performed and combined in Photoshop CS5 (Adobe Systems).

\section{Results}

In the course of a horse study on tissue-engineered cartilage regeneration, native cartilage of transplanted as well as that of control animals was analysed. In the course of these investigations, in both treated and control animals, crystals were observed in ultrathin sections in the transmission electron microscope (Figs. 1, 2, S1) and analysed with Fourier transform (Fig. 3) and element analysis (Fig. 4) in order to prove their protein crystalline character. For additional explorations on their distribution in the cartilage tissue and throughout different species, paraffin sections were screened using several stainings to further provide a rough chemical classification (Figs. 5; S2).

\section{Transmission electron microscopy}

Transmission electron microscopic images revealed the overall size of the crystal and information about its inner structure. They had an elongated outer morphology, stretching throughout the whole cell (Figs. 1, S1a) over several $\mu \mathrm{m}$ length and sometimes deforming the cell membrane

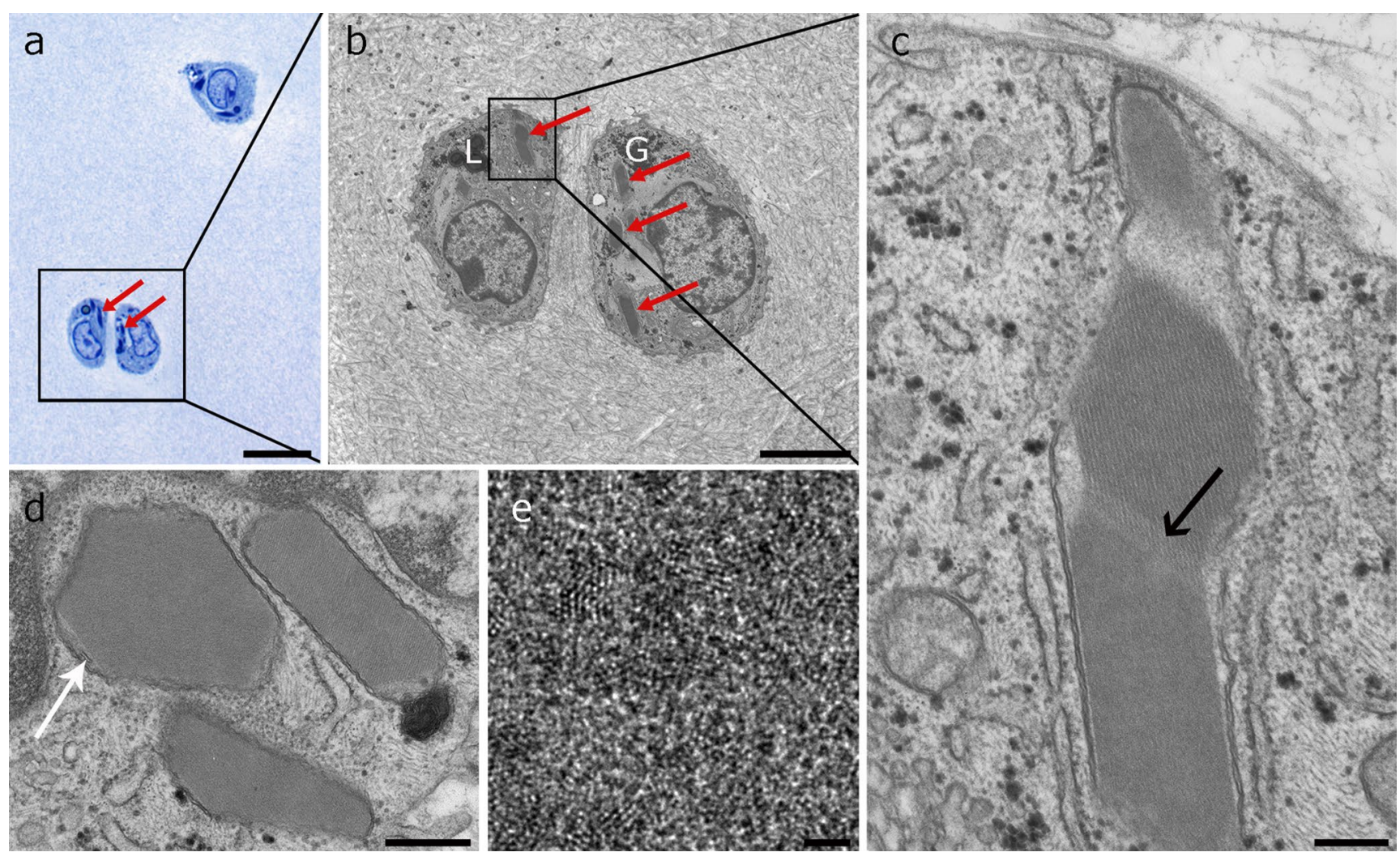

Fig. 1 Ultrastructure of intramitochondrial crystals in articular chondrocytes of juvenile horses. a Semithin resin section stained with toluidine blue showing three chondrocytes containing two types of intensively stained structures inside the cytoplasm: spherical lipid droplets and crystals (arrows). The square indicates the area of $\mathbf{b} . \mathbf{b}$ TEM image showing the same double chondron as in a bearing electron dense lipid droplets $(\mathrm{L})$ and glycogen $(\mathrm{G})$ and protein crystals (arrows). The latter have elongated and homogenous structures and a slightly darker appearance than the cytoplasm. The cell on the right contains several crystal transections. The square indicates the area of magnification of image c. c Crystal consisting of three compartments. A striated substructure is visible in the middle compartment. A less dense striated zone forms the transition to the lower compartment (arrow). The whole crystal is surrounded by a double membrane. d Three crystals with different geometric shapes surrounded by a double membrane. In the outer left-hand crystal, cristae are visible between the crystal and the mitochondrial membrane (arrow). e High magnification of the crystal structure showing the individual protein units. Scale bars are a $20 \mu \mathrm{m}, \mathbf{b} 4 \mu \mathrm{m}$, c $250 \mathrm{~nm}$, d $500 \mathrm{~nm}$ and e $2 \mathrm{~nm}$ 

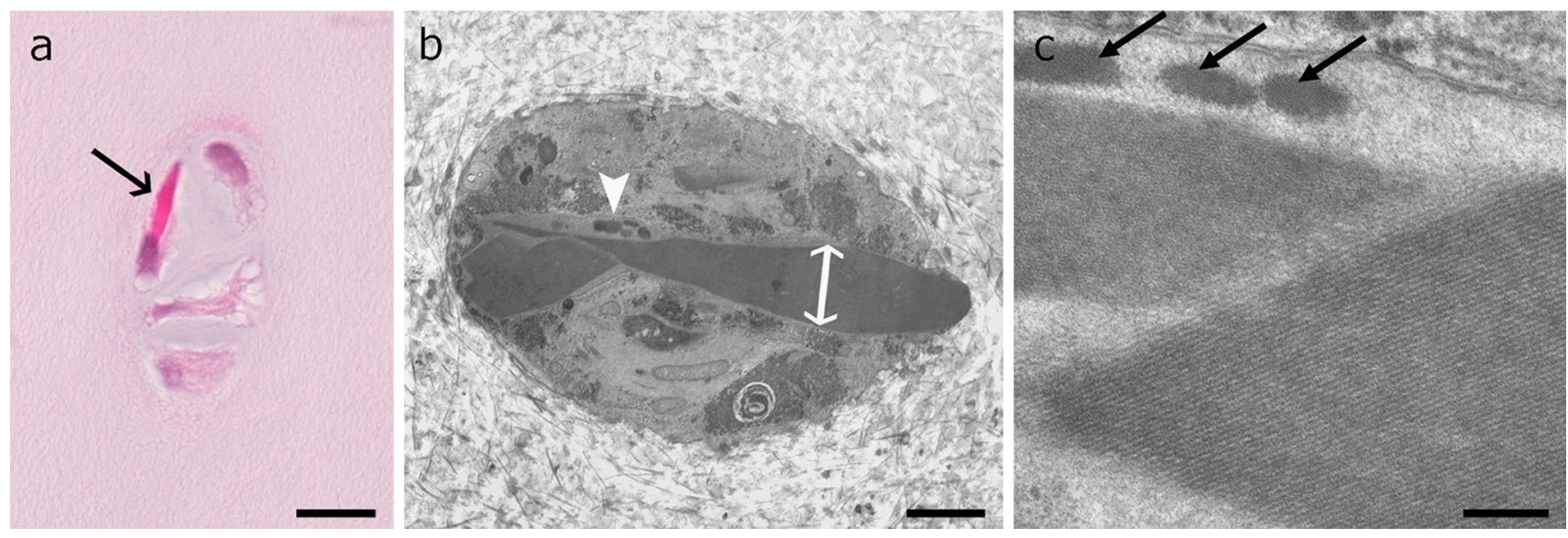

Fig. 2 Intramitochondrial crystals in adult horse chondrocytes adjacent to a defect area. a Hematoxylin-eosin-stained chondron of four chondrocytes form a small-sized cluster. One cell contains an intensively stained crystal of about $3.5 \mu \mathrm{m}$ in diameter (arrow). b TEM image showing several crystal transections in one cell with a maximal diameter of $2 \mu \mathrm{m}$ (double arrow) and extending the cell membrane by stretching beyond the natural limit of the cell. Adjacent to the large crystal homogenous dense spots indicate nucleation centres of new crystals (arrowhead). $\mathbf{c}$ Higher magnification of the interface between two crystals and three nucleation centres of further crystals (arrows). Note that the crystal on the left-hand outer side has a slightly striated substructure. Scale bars are a $20 \mu \mathrm{m}, \mathbf{b} 2 \mu \mathrm{m}$ and c $200 \mathrm{~nm}$
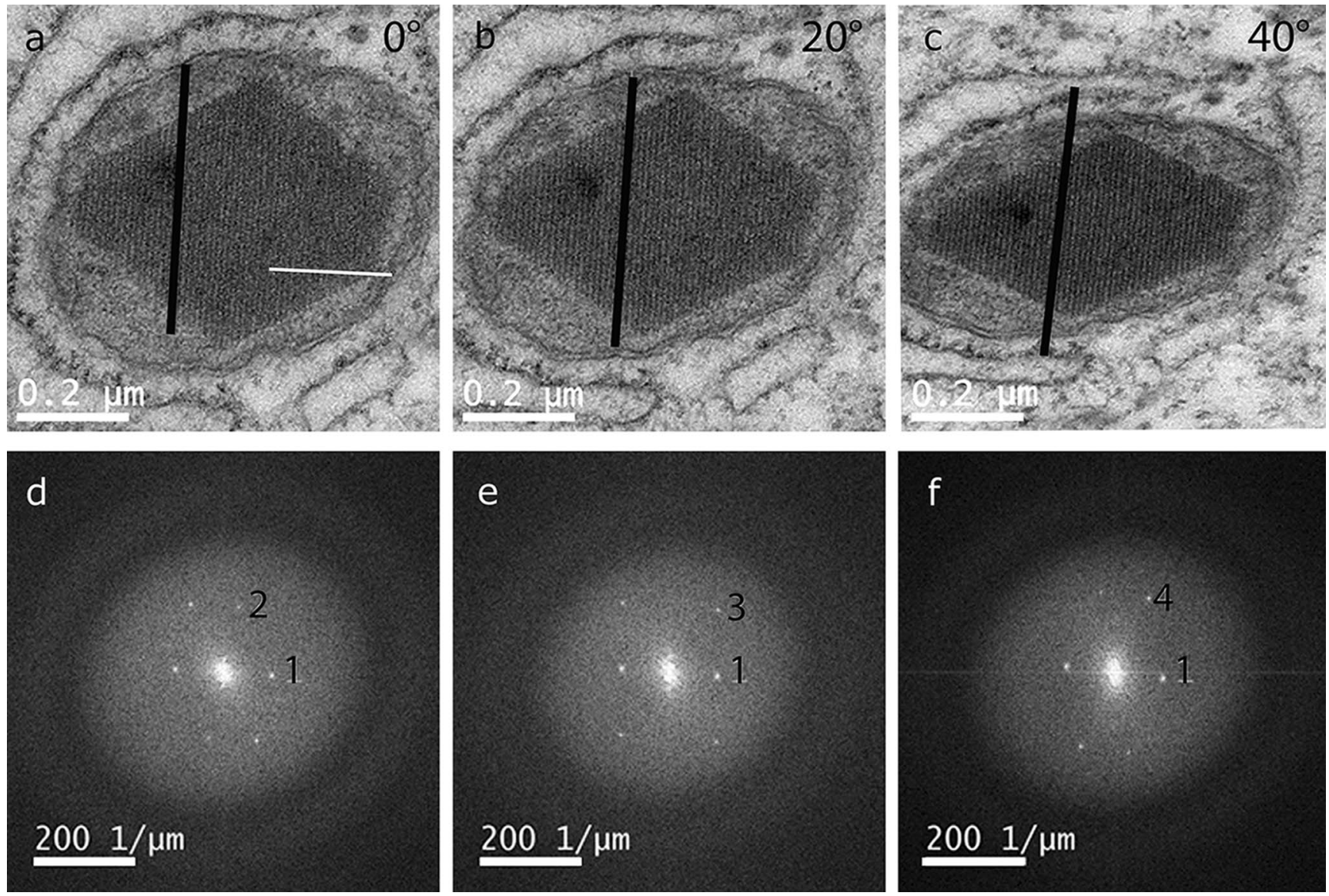

Fig. 3 Tilted TEM images and Fourier transform. a-c TEM lattice plane images of a crystal in mitochondria taken at different orientations $\left(\mathbf{a} 0^{\circ}, \mathbf{b ~} 20^{\circ}, \mathbf{c} 40^{\circ}\right)$ by systematic tilting around the white line. While one plane (parallel to the black line) is kept edge on, the 2-dimensional projections show different periodic structures. $\mathbf{d}-\mathbf{f}$ The corresponding Fourier transform images of the electron micrographs show several spots whose distance from the centre is inversely related to the lattice plane spacing. Due to the systematic tilting, spot 1 is present in all three images 

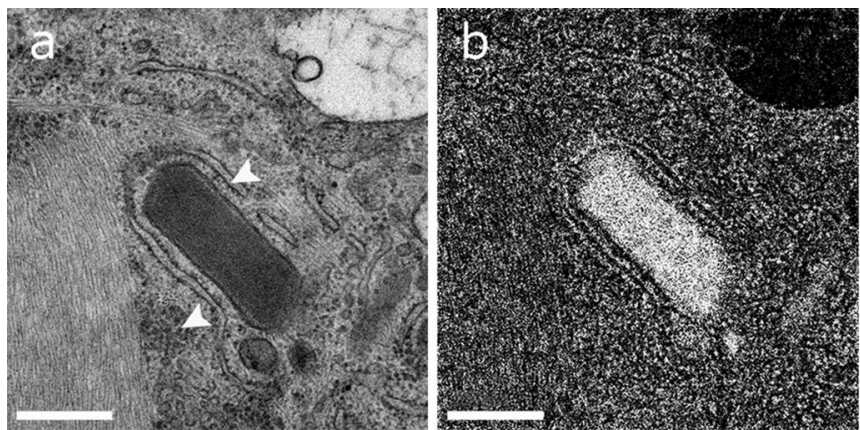

Fig. 4 Elemental distribution analysis of the crystals with EFTEM. a The zero-loss image displays the overall structure of the crystal. Arrowheads indicate ribosomes at the ER and in the cytoplasm as also indicated in c. b Nitrogen is clearly detected in the crystalline
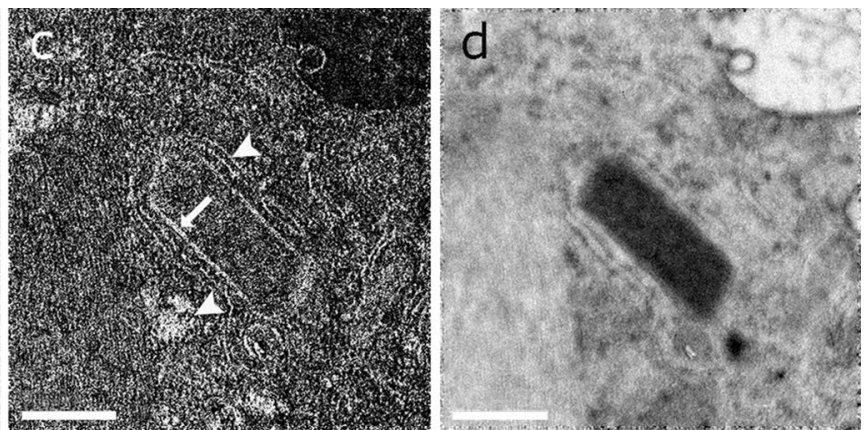

structure. c Sulphur is not positive in the crystal but the surrounding mitochondrial plasm (arrow) and the ribosomes at the ER and in the cytoplasm (arrowhead). d Phosphor did not show any signal inside the crystal. Scale bars are $0.5 \mu \mathrm{m}$

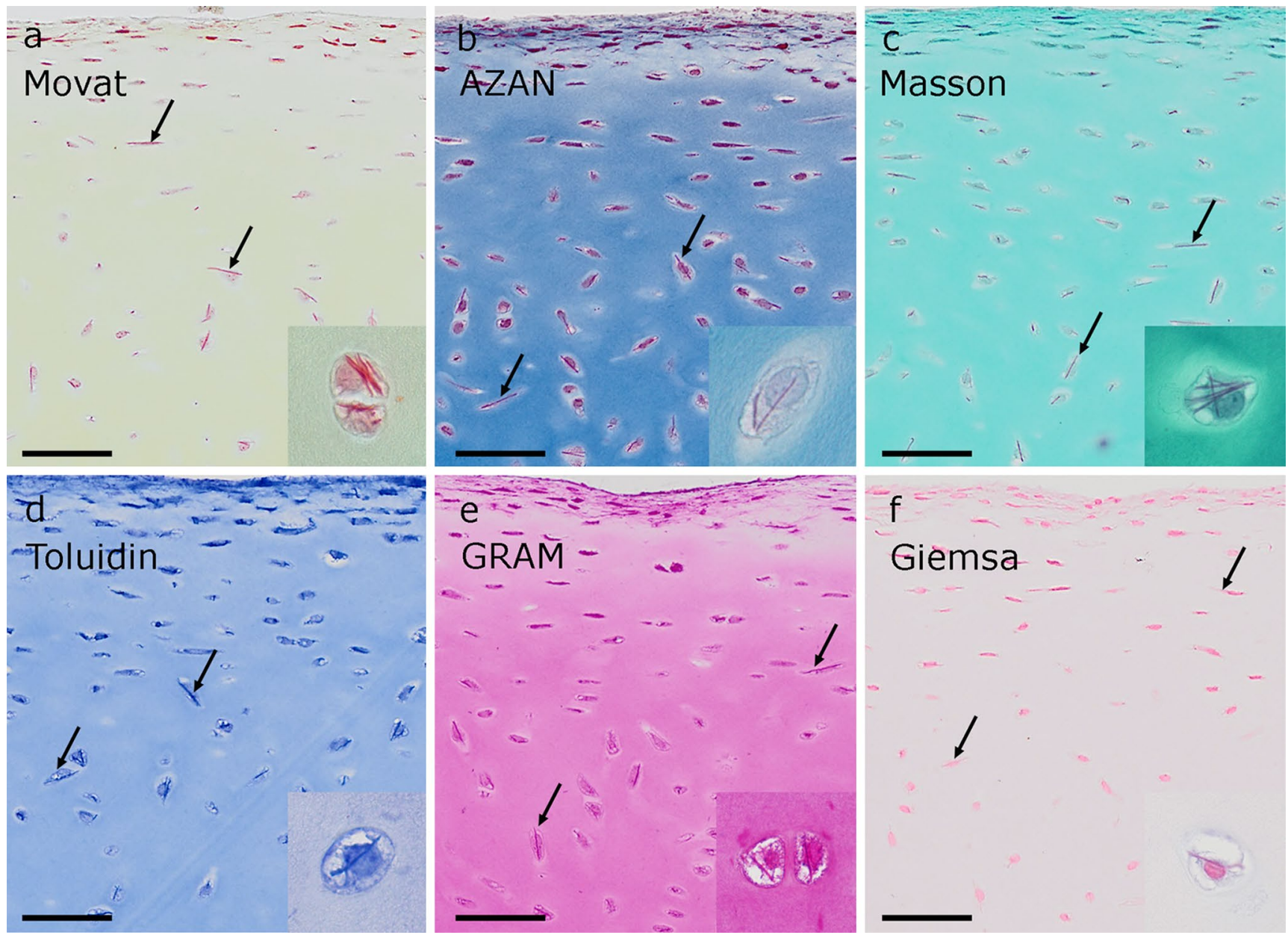

Fig. 5 Histochemical methods that intensely stain the crystals in paraffin sections. The arrows indicate two of the most striking crystals in each overview image appearing as intensively stained needles in faintly stained cells. a Movat, b AZAN and c Masson stain the cellular matrix less intensive than the crystals, resulting in a clear visualization of the crystals even in overview images. It is obvious that the crystals stretch throughout the whole cells and are orientated along their long axis and therefore in the superficial zone parallel to the joint surface. The detail images (insert) show several crystals in a single cell. d-e In toluidine blue and GRAM, the intensity of the matrix impedes a clear discrimination of the crystals in overview images, even though the detail images (insert) show that the crystals are stained. f In Giemsa, the staining of both, cytoplasm and crystal, is quite pale. Scale bars are $50 \mu \mathrm{m}$ 
when the crystal extended the limit of the cell (Fig. 2b). In cross section, they had a geometrical profile with various shapes. Typical geometric structures were hexagons with four long and two short sides (Figs. 1d, 3, S1b) or elongated hexagons with two long and four short sides (Figs. 4, 9c). Further, pentagonal or undefinable cross section structures were found. With higher magnification, the regular crystal structure became obvious (Figs. 1c, d, 2c, $3, \mathrm{~S} 1 \mathrm{~b}$ ) with parallel lines in a distance of $10 \mathrm{~nm}$. In cross or oblique section and higher magnification tightly aligned 1-2 nm granular units emerged (Fig. 1e).

In general, some crystals seemed to consist of several subunits, placed next to each other (Fig. 1c). Higher magnification revealed that they merge together by connecting crystal planes. Those subunits may have different orientations and therefore varied in the appearance of the crystalline substructure (Figs. 1c, 2c).

TEM images further revealed that the crystals were located inside mitochondria since they were surrounded by a double membrane bearing cristae in the narrow remaining space between crystal and double membrane (Fig. 1d). Occasionally the cristae were arranged to untypical network-like structures (Fig. S1c). The crystals completely filled the intramitochondrial space and seemed to stretch the mitochondrion to the length of the crystal. Non-crystal bearing mitochondria found in the same cells had normal size (200-500 $\mathrm{nm}$ in diameter).

A single mitochondrion could also have several separate crystals lying in parallel (Fig. S1b). Apart from typical crystals, deposits of a homogenous substance could be seen inside crystals-containing mitochondria. They were small with some hundred nanometre; they had a roundish shape and indefinite edges (Fig. 2b, c). A marginally darker contrast than typical crystals could be observed, and in some a slight striation was discernible. Overall, they appeared like premature crystals.

The crystalline parameters were further characterized with lattice analysis in TEM and Fourier transformation (Fig. 3). The intramitochondrial crystals were imaged along three different zone axes by tilting around a defined axis (Fig. 3a white line) with a tilt angle of $20^{\circ}$ and $40^{\circ}$ (Fig. 3b, c) with respect to the plane image (Fig. 3a). The Fourier transform images (Fig. 3d-f) show sharp spots, whose position and inverse distance from the centre are correlated to the orientation and spacing of the corresponding lattice plane, respectively. While distances and angles in the plane of projection can be measured accurately at small tilts of the sample, the uncertainty increases with the increased tilt angle. In addition, since spots in the FFT image are visible over a large tilt range (about $10^{\circ}$ ) due to the extended intensity of the spots in the direction of projection, the error of angles in the direction of projection is $\pm 3^{\circ}$. Therefore, only a list of characteristic spacing and angle $\alpha$ of lattice planes can be given (Table 1).
Table 1 Lattice plane spacing and angle $\alpha$ between planes represented by the spots denoted 1-4 in Fig. 3d-f

\begin{tabular}{lllll}
\hline Spot \# & 1 & 2 & 3 & 4 \\
\hline Lattice spacing $(\mathrm{nm})$ & $10.4 \pm 0.2$ & $7.7 \pm 0.2$ & $6.1 \pm 0.2$ & $6.5 \pm 0.3$ \\
Angle $\alpha(1 ; \#)\left({ }^{\circ}\right)$ & 0 & $80 \pm 1$ & $56 \pm 2$ & $72 \pm 3$ \\
\hline
\end{tabular}

Energy-filtered TEM (EFTEM) images were carried out to measure the composition of the crystals and the surrounding material. The protein relevant elements nitrogen $\left(E_{K}=401 \mathrm{eV}\right)$, sulphur $\left(E_{L 2,3}=165 \mathrm{eV}\right)$ and phosphor $\left(E_{L 2,3}=132 \mathrm{eV}\right)$ were acquired (Fig. 4$)$. Inside the crystals, nitrogen was increased, while sulphur could only be measured on the crystal surrounding membrane and in the cytoplasm. Phosphor was absent in the crystal.

\section{Histology}

Using light microscopy of toluidine blue-stained semithin resin sections, crystals were stained intensively and identified within the same cells as in TEM (Fig. 1a). Therefore, it was tested whether the crystals were also stained in paraffin sections, which were formalin-fixed in contrast to the glutaraldehyde and osmium tetroxide treatment used for resin sections. Using toluidine blue staining, it was equally possible to visualize the crystals in paraffin sections (Fig. 5d). In order to get more information about the histochemical properties, fourteen stainings were applied to native equine cartilage. The dyes were targeted against proteins, sugar and mucus substances (Figs. 5, S2). Crystals retained the dyes of general histological stains and appeared red, magenta or purple with Movat, AZAN, Masson, GRAM, and Giemsa and the unspecific toluidine blue (pH 9.0) staining (Fig. 5). Moderate staining was found using MSB and HE (Fig. S2a, b). Faint or no staining was evident with PAS (for sugars), Alcian blue, Safranin O (glycosaminoglycans) and Biebrich scarlet at $\mathrm{pH} 8.0$ and 10.0 (basic proteins) (Fig. S2c-f). In the polarization filter microscope, the crystals did not show any birefringence or colour effect with Picro Sirius redstained cells or any green colour effect with Kongo red (data not shown). Out of the tested dyes, Movat and AZAN (Fig. 5a, b) gave the brightest staining and best contrast to the surrounding tissue staining (Table 2).

An analysis of the crystals in paraffin sections confirmed the electron microscopic observation that they were needle-like and stretching through the whole cells (Figs. 2a, $5,6,7,8 \mathrm{~b}, \mathrm{~S} 3 \mathrm{c})$ measuring up to $25 \mu \mathrm{m}(25.5 \mu \mathrm{m}$ was the largest measured; Fig. 6b). Some crystals appeared tilted or branched (Fig. 6c), probably due to the fusing crystals seen in TEM. As in TEM, several crystals could be distinguished within one cell; they were more or less orientated along the axis of the cells (Figs. 5, 6, 7, S3). Therefore, the 

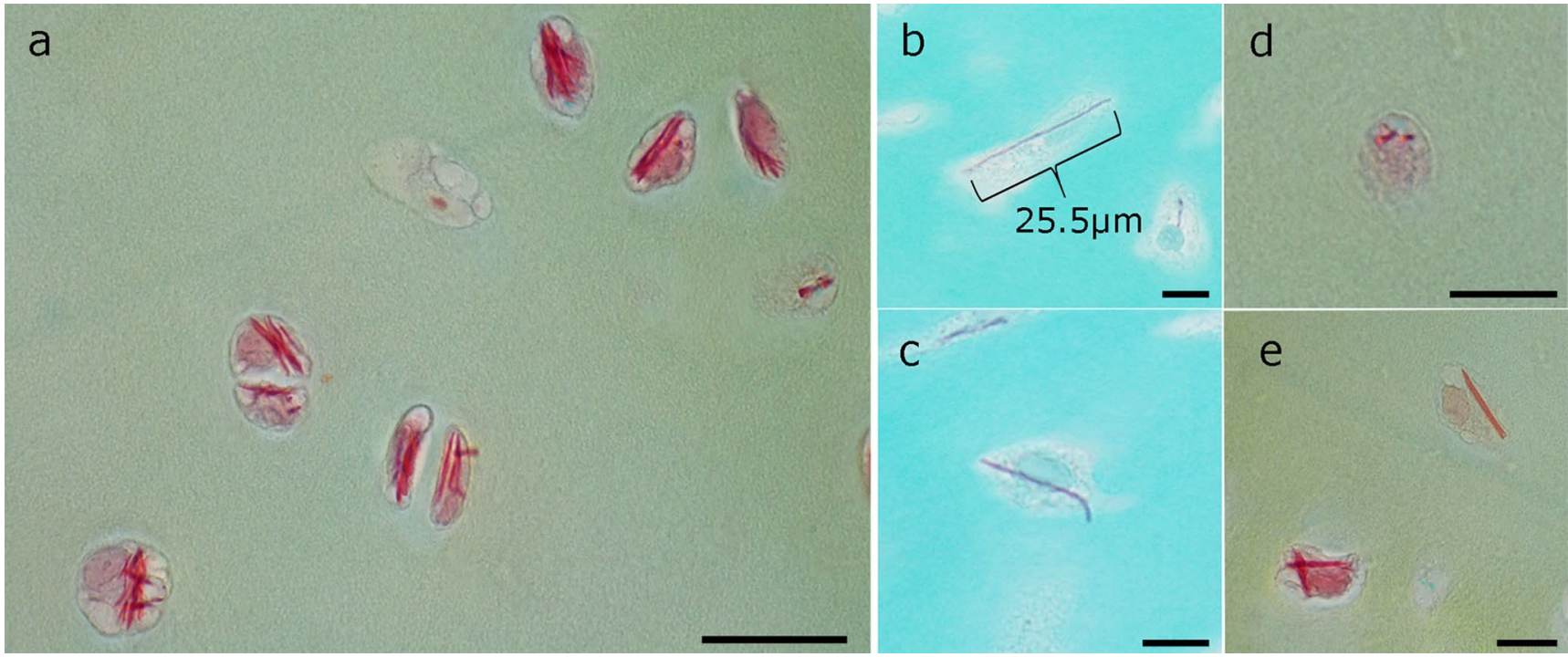

Fig. 6 Several examples of different numbers and appearance of crystals inside chondrocytes of native articular cartilage. Details of Movat (a, d, e) and Masson Trichrom $(\mathbf{b}, \mathbf{c})$ stained cartilage areas with crystals in almost all cells. a Cells contain several crystals arranged in bundles and aligned the long axis of the cell in elongated

orientation of the elongated crystal also showed a specific pattern in the tissue corresponding to the orientation of the cells. If transversely cut, the crystals were discernible as dense homogenous spots (Fig. 6d). In pale degrading cells, also the crystals change their colour from intensive red to orange, indicating that the crystal proteins altered during decay (Fig. 6e).

In order to screen the presence and distribution of crystals, a short version ("crystal-stain") of the most intensive Movat-stain was created based on Acid Fuchsin for the crystals and saffron for a faint matrix colour. This stain was then used for screenings of other species: articular cartilage from chicken, rat, pig, sheep and human and epiphyseal cartilage from rat and pig. None of those species bore crystals inside chondrocytes. However, amongst articular cartilage samples of one adult and two juvenile horses of another source, crystals were found in a 3-month-old foal (Fig. 7).

The distribution of crystal-containing chondrocytes inside the articular cartilage tissue was characterized in samples taken from various regions of the equine knee joint. Crystals were either all over the three non-calcified cartilage zones (superficial, middle and deep zones) or preferentially in the superficial and transition zones (Figs. 5, 8 and S3). They were rare in the deep zone and never detected in the calcified zone, the bone and the periost (Fig. S3). In some regions, there were only single cells containing a single crystal within the whole cartilage transection. Cartilage regions with a well-developed superficial zone with elongate chondrocytes orientated parallel to the joint surface, chondrocytes. b Crystal stretching through the whole cell measuring $25.5 \mu \mathrm{m}$. c Chondrocyte containing acrystal with bent end. d In cross section through the crystals, they appear as intensive red dots. e Chondrocyte with crossed crystal bundles and a faintly stained cell with a slightly orange crystal. Scale bars a $20 \mu \mathrm{m}, \mathbf{b}-\mathbf{e} 10 \mu \mathrm{m}$

contained more crystals than areas with spherical chondrocyte appearance even close to the cartilage surface (Fig. 8). This was also found within one and the same cartilage samples (Fig. 8). With frequency of crystal-containing chondrocytes, also the amount of crystals per cell increased (Fig. 6). The highest amount of crystals identified in a cell was six.

In the samples of the Haflinger horses from the cartilage regeneration study, all five yearlings bore crystals, while in the adult individuals crystals were less frequent and were found in three out of 19 horses. In two of the latter animals, larger and more intensively stained crystals (Fig. 2) were found in restricted areas adjacent to the defects. The mitochondria with the crystals also contained several dark homogenous nucleation centres indicating the formation of further crystals (Fig. 2c). Those areas were in both samples adjacent to the defect area. We also screened the regenerative tissue found in the defect areas: In the group treated with scaffold transplants, no crystals were present. In the transplantation site, crystals were present only in the regenerative tissue, which developed from scaffold-free transplant based on equine chondrocytes grown under mechanical stimulation (Fig. 9).

\section{Discussion}

In the current study, giant crystals inside mitochondria of equine articular cartilage chondrocytes were analysed with morphological methods and results were compared with 


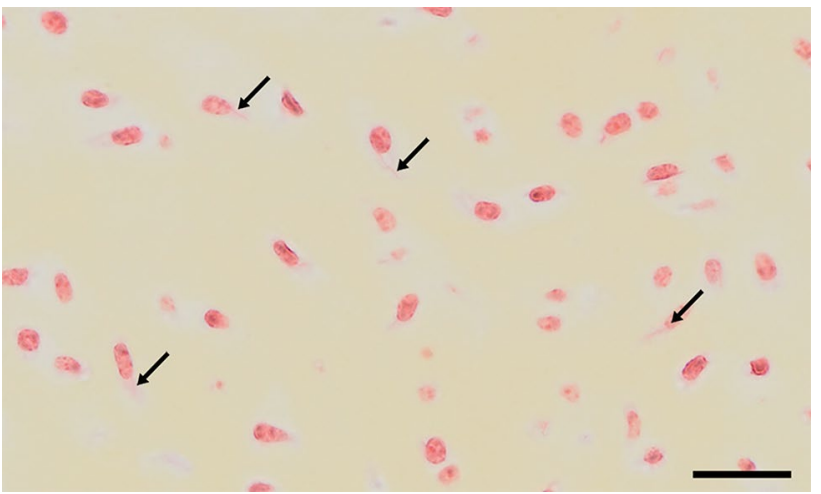

Fig. 7 Cartilage of a 3-month-old foal stained with "crystal-stain", a short version of Movat based on acid fuchsin and saffron. Several cells bear crystals (arrows) stretching throughout the whole cell. Scale bar $50 \mu \mathrm{m}$

data of the current literature. Most literature data of intramitochondrial crystals in general are from the booming period of ultrastructure, the 1970s, which is probably due to the fact that crystal formation in mitochondria could not be experimentally manipulated, as it is the case for organelles such as ER and peroxisomes (Sawaya et al. 2014; Schonherr et al. 2015; Tsutsui et al. 2015). Therefore, the main information available is on ultrastructure.

At any rate, there are many descriptions of intramitochondrial crystals, especially in lower organisms such as protozoa (Suganuma and Yamamoto 1980) and invertebrate (Davis 1967; Hawkins et al. 1980) but also vertebrate (Hawkes 1993; Ward 1962) including Mammalia (Saito and Fleischer 1971; Shiraki and Neustein 1971). Those crystals have either only an inner crystalline structure (Bhagwat and Ross 1971; Saito and Fleischer 1971) or also a crystalline outer shape (Suganuma and Yamamoto 1980; Ward 1962). They appear in different cell types but with higher frequency in liver and muscle under pathological conditions such as ischaemia (Hanzlikova and Schiaffino 1977; Shiraki and Neustein 1971; Swenson et al. 1967), protein deficiency or starvation (Ericsson et al. 1966; O'Gorman et al. 1997; Taira 1979) or intoxication with alcohol (Voelz 1968) and different types of myopathies (Farrants et al. 1988).

The current study is to our knowledge the first one characterizing extensive protein crystals in mitochondria of chondrocytes. In one publication describing the ultrastructure of equine cartilage, crystals were mentioned and shown in ultrastructural images of equine chondrocyte (Horký and Tichý 2002) but without any description of their subcellular localization and structure. Shape and size of those crystals were the same as in this study, and samples were also taken from articular cartilage of horse. Crystals in chondrocytes have never been described in other species, not even in the studies on canine and feline cartilage performed by the authors who described the presence of crystals in horse chondrocytes (Horký and Tichý 1995, 2004). In order to verify the absence of crystals in other than equine articular cartilage, this study encompassed a screening of cartilage from various species, including different cartilage types (articular, epiphyseal) and ages (skeletal immature vs. adult) based on histological sections. No crystalline inclusions were identified neither in chicken, rat, pig, sheep, calf nor in human. However, when screening horse cartilage harvested and processed in other institutes, foal cartilage also showed mitochondrial crystals. This matched well with the observations made in the samples of the main study that crystals appeared with higher frequency in juvenile horses than in adults.

As in the present study, intramitochondrial crystals in other cell types have been described to be frequently found in giant mitochondria (Bhagwat and Ross 1971; Ghadially and Parry 1966). In contrast to the crystals in the equine chondrocytes, those crystals were clearly smaller than the mitochondria, frequently compartmented and occupied only a part of the organelle. They did not seem to be the reason for the size increase of the mitochondria. On the contrary, in the equine chondrocytes the increasing size of the crystals may be the obvious reason for the enlargement of the mitochondria, since the crystals completely fill the intramitochondrial space and stretch the mitochondrion to an enormous size, sometimes to the full length of the cell. Further, in horse chondrocytes, giant mitochondria only appear in relation with giant crystals. Some crystals were perfectly straight and continuous, suggesting that they developed by continuous growth; others were angulated and surrounded by a mitochondrial membrane that appeared to be segmented, indicating that the size increase occurred by fusion of several mitochondria. Fusion of mitochondria is a normal physiological process and renewal strategy for exchange of information and material (Pernas and Scorrano 2016; Westrate et al. 2014). It is conceivable that in chondrocytes, the growing mitochondria merge at a certain point due to steric reasons and fuse.

Previous studies have suggested that crystals may be caused by retard fixation (Pena 1980) due to disintegrating proteins and lipids during autolysis. Crystals were not found when tissues were fixed immediately. Such artefacts were formed in the intracristae space and had completely different morphology and size than those present in the mitochondrial plasma of chondrocytes. They appeared as dots, filaments, microtubes, parallel arrays forming sheets, or coiled filaments arranged to helical structures; but they remained within the size of the intracristae space. They were found in neurons (Pena 1980); also similar structures have been described in various other kinds of tissues (Barastegui and Ruano-Gil 1984; Hall and Crane 1971).

In the present study on horse cartilage, such artefacts can largely be excluded, since samples were processed directly 


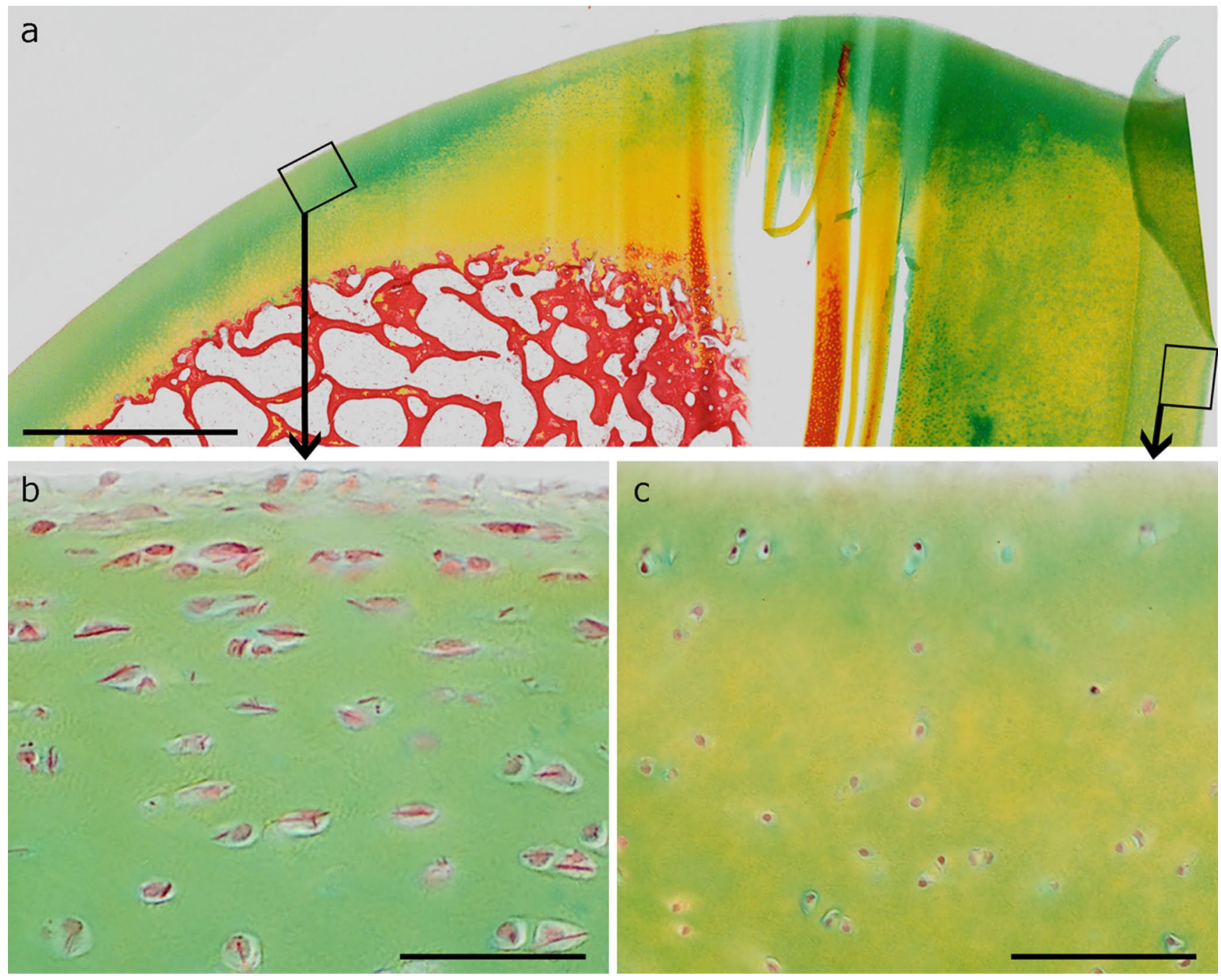

Fig. 8 Movat staining of native articular cartilage with several morphological regions correlating with different frequency of crystals. The squares in the overview (a) indicate the area of magnification in b and c. b The thinner cartilage region with elongated chondrocytes

after harvest, and in addition articular cartilage is not as sensitive to changes in the environment as it is the case for neurons or muscle, since chondrocytes are embedded within a dense protecting matrix (Nürnberger et al. 2006b) and are marginally physiologically active. Further, samples of human articular cartilage analysed in this and previous studies (Nürnberger et al. 2006a, b) taken from femoral head replacement surgery did not show any crystals even though they were processed at different time points after surgery (immediately up to several days). Fixation artefacts should also be excluded, since the crystals were present in samples of the same individuals after treatment protocols by means of two different methods (histology and electron microscopy) and crystals were not found in cartilage or other samples of non-equine cartilage processed in the in the superficial layer contain chondrocytes with crystals in almost every cell, whereas no crystals are visible in the thick cartilage region with mainly spherical chondrocytes up to the cartilage surface (c). Scale bars a $2 \mu \mathrm{m}, \mathbf{b}$ and $\mathbf{c} 50 \mu \mathrm{m}$

same way. In addition, the size of the chondrocyte crystals (several $\mu \mathrm{m}$ ) stretching almost through the whole cell indicates that not only the crystals but also the mitochondria had to grow to a multiple of their original size. It is unlikely that chondrocytes which have a low metabolic activity are capable to synthesize and accumulate proteins of this amount in the course of sample preparation until fixation is completed.

The number of crystals per section varied from none up to six that were distributed singularly or in groups in one or few mitochondria, while most mitochondria of the cells were normal-sized and did not contain any crystals. This raises the question why protein aggregates are not regularly distributed over all mitochondria of one cell, but they accumulate in specific ones. It is a known fact that 


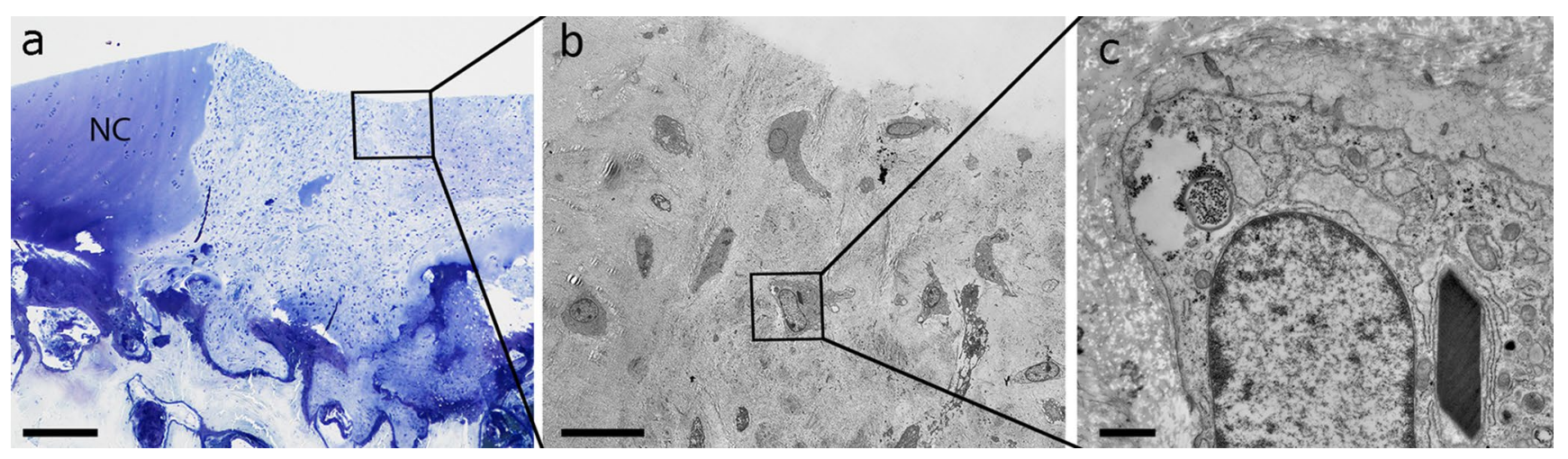

Fig. 9 Defect area and regenerative tissue of an experimental cartilage defect in a yearling horse. It was treated with a scaffold-free chondrocyte construct produced under mechanically stimulation in vitro. a Toluidine blue-stained overview image showing the transition zone of native cartilage (NC) and regenerative tissue in the defect area. The square indicates the area shown in the TEM image (b). b The TEM image shows polygonal and spherical cells inside the tissue surrounded by dense matrix. The square in $\mathbf{b}$ indicates the cell which is enlarged in c. c A rhomboidal crystals is visible inside the cell. Scale bars a $250 \mu \mathrm{m}$, b $20 \mu \mathrm{m}$ and c $1 \mu \mathrm{m}$ alterations concern only one or few mitochondria per cell, such as the enlargement to giant mitochondria (Tandler and Hoppel 1986). This individual reaction of mitochondria is probably related to the fact that cells may contain different subpopulations of those respiratory organelles, which vary in morphology (small globular or elongated), production of reactive oxygen species, or calcium content and membrane potentials (Banerjee et al. 2015; Kuznetsov et al. 2006). Membrane potentials are related with the trans-membrane transport mechanisms, such as inner and outer membranes transport TIM and TOM (Pfanner and Meijer 1997). A malfunction of one of the transport channels could be the reason for such accumulation: either by excess import of proteins or when proteins produced in the mitochondria exceed the discharging capacity towards the cytoplasm, similar to the experimentally induced IgGaccumulation in the endoplasmic reticulum of the Chinese hamster ovary cells after disequilibrium of $\mathrm{IgG}$ protein synthesis and transport to the Golgi apparatus (Hasegawa et al. 2011). Also the voltage-dependent anion channel (VDAC) is located in the outer mitochondrial membrane and responsible for transport of small molecule and ions (Lemasters and Holmuhamedov 2006). VDAC could also be responsible for protein accumulation inside the chondrocytes mitochondria, which is supported by the fact that it is voltage-dependent and mitochondrial subpopulations differ in their membranes potential (as discussed above). Inhibition of VDAC results in general mitochondrial suppression and is induced by circumstances which were also reported in relation with crystal formation in mitochondria such as the influence of ethanol (Voelz 1968), anoxia and hypoxia (Shiraki and Neustein 1971). Hypoxia is also present in cartilage and may exceed a certain limit in specific cartilage regions and during growth, leading to closure of the VDAC and accumulation of small proteins starting to crystallize in the mitochondria due to stochastic reasons. Considering the size of the crystals and the hypothesized loss of functionality of the mitochondria, the question arises whether the cells and the cartilage are still intact. The lack of interference with the vitality of the chondrocytes is probably due to an increased glycolysis, which is also part of the normal physiological condition in the unvascularized cartilage tissue (Nürnberger et al. 2006b).

In order to obtain further information about the nature of the crystals, fourteen histochemical staining methods were performed. Most intensive staining was achieved with anionic dyes such as Movat and Masson Goldner trichrom, further AZAN, GRAM, Giemsa and toluidine blue. Little stain affinity showed MSB and HE but not at all with Alcian blue, Safranin O, PAS, BBS and Picro Sirius red. This staining reactivity is similar but not identical to the well-characterized Reinke's crystals of Leydig cells. Reinke's crystals also have affinity to the anionic acid fuchsin in trichrom and GRAM staining (Mesa et al. 2015). PAS, in contrast, showed to some degree staining of Reinke's crystals but did not stain crystals in the mitochondria, indicating the absence of polysaccharides. This shows that crystals differ in their composition and that equine chondrocytes crystals are not glycosylated proteins or they are only to a small extent.

The analysis of elements performed in this study revealed the presence of nitrogen, which is a typical component of proteins. However, it was not possible to achieve any further identification of a specific substance. The lack of sulphur and phosphor excludes nucleic acid. Sulphur was, however, found around the crystal and in the ribosomes at the ER and in the cytoplasm. This signal could probably derive from cystine of the ribonucleic acid of ribosomes. Similarly, Fourier transform analysis of the periodic function of the lattice has proven a regular 
Table 2 Stainings used for crystal detection and rough identification of its nature

\begin{tabular}{|c|c|c|c|c|}
\hline Method & General staining of equine articular cartilage & Crystal colour & Crystal staining dye & Interpretation \\
\hline Movat Pentachrom stain & $\begin{array}{l}\text { Nuclei reddish purple, cytoplasm pale reddish } \\
\text { lilac; cartilage green, bone yellow, muscle red }\end{array}$ & Intensively red to purple & Acid fuchsin & \\
\hline $\begin{array}{l}\text { Short Movat } \\
\text { Crystal stain }\end{array}$ & $\begin{array}{l}\text { Nuclei red, cytoplasm pale; } \\
\text { cartilage yellow }\end{array}$ & Intensively red & Acid fuchsin & \\
\hline $\begin{array}{l}\text { AZAN } \\
\text { Trichrome stain }\end{array}$ & $\begin{array}{l}\text { Nuclei reddish purple, cytoplasm pale purple; } \\
\text { collagen blue }\end{array}$ & Magenta & Azo carmine & \\
\hline $\begin{array}{l}\text { Masson Goldner } \\
\text { Trichrome stain }\end{array}$ & $\begin{array}{l}\text { Nuclei bluish purple or green, cytoplasm pale } \\
\text { lilac or pale green } \\
\text { cartilage green, muscle red }\end{array}$ & Magenta & Acid fuchsin & $\begin{array}{l}\text { Similar but more intense colouring of crystals in } \\
\text { comparison with cytoplasm and nuclei indicate } \\
\text { dense packing of cellular substances }\end{array}$ \\
\hline $\begin{array}{l}\mathrm{HE} \\
\text { General tissue stain }\end{array}$ & $\begin{array}{l}\text { Nuclei bluish purple, cytoplasm pale lilac; matrix } \\
\text { pink-lilac }\end{array}$ & Magenta & Eosin & \\
\hline $\begin{array}{l}\text { Giemsa } \\
\text { General cell stain }\end{array}$ & $\begin{array}{l}\text { Nuclei pink, cytoplasm pale pink or unstained; } \\
\text { matrix pink }\end{array}$ & Magenta & Thiazine-eosinate & \\
\hline $\begin{array}{l}\text { GRAM } \\
\text { Bacterial stain }\end{array}$ & $\begin{array}{l}\text { Gram-positive bacteria purple-blue, gram-nega- } \\
\text { tive pink }\end{array}$ & Magenta & Carbol Fuchsin & \\
\hline $\begin{array}{l}\text { MSB } \\
\text { Trichrome stain }\end{array}$ & $\begin{array}{l}\text { Nuclei pale bluish purple or red; cytoplasm } \\
\text { unstained; collagen blue, fibrin red, muscle red, } \\
\text { erythrocytes yellow }\end{array}$ & Only individual crystals faintly reddish & Crystal Ponceau 6C & $\begin{array}{l}\text { As above; variable staining indicates different } \\
\text { density }\end{array}$ \\
\hline $\begin{array}{l}\text { Toluidine blue } \mathrm{pH} 9.0 \\
\text { General tissue stain }\end{array}$ & General intensive blue staining of cells and matrix & Unspecific & Toluidine blue & Dense consistence \\
\hline $\begin{array}{l}\text { PAS } \\
\text { Secretion stain }\end{array}$ & Polysaccharides purple; cells and matrix pale lilac & Yellowish inherent colour & None & No/undetectable glycosylation of proteins \\
\hline $\begin{array}{l}\text { Alcian blue } \\
\mathrm{pH} 2.5 \text { Matrix stain }\end{array}$ & $\begin{array}{l}\text { Glycosaminoglycans (carboxylated and sul- } \\
\text { phated) blue }\end{array}$ & Yellowish inherent colour & None & No glycosaminoglycans \\
\hline $\begin{array}{l}\text { Safranin O } \\
\text { Matrix stain }\end{array}$ & Glycosaminoglycans red & Yellowish inherent colour & None & No glycosaminoglycans \\
\hline $\begin{array}{l}\text { Biebrich scarlet } \\
\text { Protein stain }\end{array}$ & Basic proteins pink & Yellowish inherent colour & None & No basic proteins \\
\hline $\begin{array}{l}\text { Picro Sirius red } \\
\text { Collagen stain }\end{array}$ & $\begin{array}{l}\text { Collagen has various colours in polarization } \\
\text { microscopy }\end{array}$ & Yellowish inherent colour & None & No birefringence \\
\hline $\begin{array}{l}\text { Kongo red } \\
\text { Amyloid stain }\end{array}$ & Amyloid green in polarization microscopy & Yellowish inherent colour & None & No amyloids \\
\hline
\end{tabular}

arrangement of the substructure that is typical for protein crystals. The parameters of the unit cell could, however, not be identified completely.

Due to the specific activity of some cell types, especially hormone-expressing cells, it has been possible to identify in such cases the composition of the crystals by immunostaining. Therefore, it is known that Reinke's crystals in the Leydig cells contain the androgen-specific steroidogenic

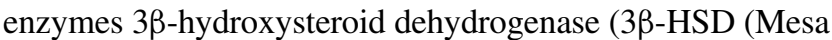
et al. 2015) and $\beta$-cells in developing pancreas insulin crystals (Riopel et al. 2014). It is further known that under the systemic disorder histocytosis macrophages and dendritic cells accumulate immunoglobulins (Dogan et al. 2012). Articular chondrocytes do not have a particularly increased enzymatic or synthetic activity, but are challenged with a hypoxic and load bearing environment. It is therefore possible that either hypoxia or mechanical stress are related with crystal formation, leading to a hyperactivity or disequilibrium of proteins with changing load conditions during growth or higher activity in young individuals. Hormonal reasons seem less likely to be influential, since crystals did also appear in some adult horses to a certain extent. This supports the hypothesis of an imbalanced production and mitochondrial transport-as discussed before. The fact that horses are heavy and athletic animals with especially high challenge in both static and dynamic mechanical stress on their joints may explain why crystals have not been found in other species so far. The higher frequency of crystals in younger individuals suggests a correlation between mechanical stress and the location and frequency of crystals. Thinner cartilage areas with elongated chondrocytes in the superficial zone bear more crystals than thick zones with rather spherical chondrocytes up to the surface. Both shape and orientation of chondrocytes are closely related to collagen alignment, and load deformation of the collagen network is transferred to the cells. In a study in foals, cartilages of two sites of the metacarpophalangeal joints were compared in terms of their changes in collagen architecture upon mechanical loading (Brama et al. 2009). One of the sites was isolated from an area challenged dynamically during jumping and galloping, and the other one from an area mainly loaded during standing. Dynamic, peak-loaded sites revealed higher changes than the constantly loaded one. The peak-load sites correspond morphologically to the equine cartilage areas with high crystal occurrence, which supports the theory that crystal formation is related to dynamic mechanical conditions. Further support is given by the fact that highest changes in collagen architecture (parallelism) during loading were detected in the upper cartilage area (Brama et al. 2009), which was also the area of highest crystal incidence in the current study. The mechanical stress that induces crystal formation could not only activate mitochondrial pathways but it also influences both the transport mechanism and the orientation of the crystals. The latter is 
supported by experimental results on shear-induced selfassembly of proteins into fibrils studied by atomic force microscopy and on high-stress shear-induced crystallization of polymers monitored by in situ X-ray scattering (Greving et al. 2012). Further indications for a biomechanical induction come from the conducted chondrocyte transplanting study. Areas adjacent to the defects bore crystals with especially large diameters. Furthermore, defects treated with in vitro stimulated constructs (Ponomarev et al. 2014) contained chondrocytes with crystals, but not those which were treated with statically cultured chondrocytes on a biomaterial (Nürnberger et al. 2013b).

\section{Conclusion}

In this study, protein crystals inside mitochondria of equine chondrocytes are described in terms of their structural grid parameter and their histochemical characteristics. These crystals have presented special characteristics in terms of their size and appearance in chondrocytes, which are cells with low metabolic activity under no particular hormonal influence. The samples in this study presented no previous history of articular cartilage disease. Some of the horses were, however, part of a study on cartilage regeneration. The distribution of the crystals suggested a relation to areas of high mechanical stress, which could locally be the case in defects and in transplanted areas. Crystals were found especially in yearlings, suggesting also a developmental component, probably due to the anatomical changes and activities during growth. Blockade of mitochondrial transport mechanisms is a possible underlying mechanism for protein accumulation. Further studies on the composition of the crystals are necessary to understand the origin and reason for their development and physiological correlations.

\begin{abstract}
Acknowledgements Open access funding provided by Medical University of Vienna. The authors would like to thank the 'Cell Imaging and Ultrastructure Research Unit' (CIUS) at the University of Vienna for providing the equipment for the electron microscopic sample preparation. Electron microscopic data were recorded in part at CIUS, further the EM Facility of the Vienna Biocenter Core Facilities $\mathrm{GmbH}$ (VBCF), Austria, the Faculty of Physics, University of Vienna and the Fraunhofer Institute for Manufacturing Technology and Advanced Materials. We thank Dr. Sonja Walzer from the Department of Orthopedics from the Medical University of Vienna, Dr. Cordula Gabriel and Prof. Heinz Redl from the Ludwig Boltzmann Institute for Experimental and Clinical Traumatology for providing histological slides or sections from previous studies.
\end{abstract}

Funding The study was partially funded by the EuroNorm Germany 1090/03 titled "Verfahren zur Therapie cartilaginärer Schäden", the EU-Project FA735A0104 titled "A Systematic Approach to Tissue Engineering Processes and Products (STEPS)" and the EU COST Action TD0906 "Biological adhesives: from biology to biomimetics" as well as CA15216 "European Network of Bioadhesion Expertise: Fundamental Knowledge to Inspire Advanced Bonding Technologies". The funding sources were involved neither in the design, data collection, analysis and interpretation nor in the writing and submission of this manuscript.

\section{Compliance with ethical standards}

Conflict of interest The authors declare that they have no conflict of interest except of the research grants mentioned in the funding section.

Ethical approval All applicable international, national and/or institutional guidelines for the care and use of animals were followed. All procedures performed in studies involving animals were in accordance with the ethical standards of the institution or practice at which the studies were conducted.

Open Access This article is distributed under the terms of the Creative Commons Attribution 4.0 International License (http://creativecommons.org/licenses/by/4.0/), which permits unrestricted use, distribution, and reproduction in any medium, provided you give appropriate credit to the original author(s) and the source, provide a link to the Creative Commons license, and indicate if changes were made.

\section{References}

Acharya KR, Ackerman SJ (2014) Eosinophil granule proteins: form and function. J Biol Chem 289:17406-17415

Bancroft J, Gamble M (2008) Theory and practice of histological techniques, 6th edn. Elsevier, China

Banerjee A, Weidinger A, Hofer M, Steinborn R, Lindenmair A, Hennerbichler-Lugscheider S, Eibl J, Redl H, Kozlov AV, Wolbank S (2015) Different metabolic activity in placental and reflected regions of the human amniotic membrane. Placenta 36:1329-1332

Barastegui CA, Ruano-Gil D (1984) Atypical cristae (paracrystalline inclusions) in mitochondria of epithelial cells of the rat ureter. I. Ultrastructural features. J Submicrosc Cytol 16:299-305

Bechtel DB, Bulla LA Jr (1976) Electron microscope study of sporulation and parasporal crystal formation in Bacillus thuringiensis. J Bacteriol 127:1472-1481

Bhagwat AG, Ross RC (1971) Hepatic intramitochondrial crystalloids. Arch Pathol 91:70-77

Brama PA, Holopainen J, van Weeren PR, Firth EC, Helminen HJ, Hyttinen MM (2009) Effect of loading on the organization of the collagen fibril network in juvenile equine articular cartilage. J Orthop Res 27:1226-1234

Davis LE (1967) Intramitochondrial crystals in Hydra. J Ultrastruct Res 21:125-133

Djaldetti M, Feller N (1978) Crystalline cytoplasmic inclusions in the liver cells of two mongrel dogs. Res Exp Med (Berl) 173:279-283

Dogan S, Barnes L, Cruz-Vetrano WP (2012) Crystal-storing histiocytosis: report of a case, review of the literature (80 cases) and a proposed classification. Head Neck Pathol 6:111-120

Ericsson JL, Orrenius S, Holm I (1966) Alterations in canine liver cells induced by protein deficiency. Ultrastructural and biochemical observations. Exp Mol Pathol 5:329-349

Farrants GW, Hovmoller S, Stadhouders AM (1988) Two types of mitochondrial crystals in diseased human skeletal muscle fibers. Muscle Nerve 11:45-55 
Ghadially FN, Parry EW (1966) Ultrastructure of a human hepatocellular carcinoma and surrounding non-neoplastic liver. Cancer 19:1989-2004

Gouranton J, Thomas D (1974) Cytochemical, ultrastructural, and autoradiographic study of the intranuclear crystals in the midgut cells of Gyrinus marinus Gyll. J Ultrastruct Res 48:227-241

Greving I, Cai M, Vollrath F, Schniepp HC (2012) Shear-induced selfassembly of native silk proteins into fibrils studied by atomic force microscopy. Biomacromolecules 13:676-682

Hall JD, Crane FL (1971) Intracristal rods. A new structure in beef heart mitochondria. J Cell Biol 48:420-425

Hamilton DW, Fawcett DW, Christensen AK (1966) The liver of the slender salamander Batrachoseps attenuatus. I. The structure of its crystalline inclusions. Z Zellforsch Mikrosk Anat 70:347-363

Hanzlikova V, Schiaffino S (1977) Mitochondrial changes in ischemic skeletal muscle. J Ultrastruct Res 60:121-133

Hasegawa H, Wendling J, He F, Trilisky E, Stevenson R, Franey H, Kinderman F, Li G, Piedmonte DM, Osslund T, Shen M, Ketchem RR (2011) In vivo crystallization of human IgG in the endoplasmic reticulum of engineered Chinese hamster ovary (CHO) cells. J Biol Chem 286:19917-19931

Hawkes F (1993) Presence of a crystal in the cytoplasm of the male germ cells of the garden dormouse Eliomys quercinus L. J Submicrosc Cytol Pathol 25:407-415

Hawkins WE, Howse HD, Foster CA (1980) Prismatic cristae and paracrystalline inclusions in mitochondria of myocardial cells of the oyster Crassostrea virginica Gmelin. Cell Tissue Res 209:87-94

Hofer F, Grogger W, Kothleitner G, Warbichler P (1997) Quantitative analysis of EFTEM elemental distribution images. Ultramicroscopy 67:83-103

Horký D, Tichý F (1995) Ultrastructure of feline articular cartilage in the postnatal period. Acta Vet Brno 64:63-70

Horký D, Tichý F (2002) Submicroscopic structure of equine articular cartilage. Acta Vet Brno 71:151-157

Horký D, Tichý F (2004) Submicroscopic structure of canine articular cartilage. Vet Med Czech 49:207-216

Jain M, Aiyer HM, Bajaj P, Dhar S (2001) Intracytoplasmic and intranuclear Reinke's crystals in a testicular Leydig-cell tumor diagnosed by fine-needle aspiration cytology: a case report with review of the literature. Diagn Cytopathol 25:162-164

Jones D, Bhatia VK, Krausz T, Pinkus GS (1999) Crystal-storing histiocytosis: a disorder occurring in plasmacytic tumors expressing immunoglobulin kappa light chain. Hum Pathol 30:1441-1448

Kiernan JA (1999) Histological and histochemical methods: theory and practice, 3rd edn. Butterworth Heinemann, Oxford

Klepal W, Rentenberger C, Zheden V, Adam S, Gruber D (2010) Structural peculiarities of the penis of Semibalanus balanoides (Linnaeus, 1767) and Chthamalus stellatus (Poli, 1791) (Crustacea: Cirripedia: Thoracica). J Exp Mar Biol Ecol 392:228-233

Koopmann R, Cupelli K, Redecke L, Nass K, Deponte DP, White TA, Stellato F, Rehders D, Liang M, Andreasson J, Aquila A, Bajt S, Barthelmess M, Barty A, Bogan MJ, Bostedt C, Boutet S, Bozek JD, Caleman C, Coppola N, Davidsson J, Doak RB, Ekeberg T, Epp SW, Erk B, Fleckenstein H, Foucar L, Graafsma H, Gumprecht L, Hajdu J, Hampton CY, Hartmann A, Hartmann R, Hauser G, Hirsemann H, Holl P, Hunter MS, Kassemeyer S, Kirian RA, Lomb L, Maia FR, Kimmel N, Martin AV, Messerschmidt M, Reich C, Rolles D, Rudek B, Rudenko A, Schlichting I, Schulz J, Seibert MM, Shoeman RL, Sierra RG, Soltau H, Stern S, Struder L, Timneanu N, Ullrich J, Wang X, Weidenspointner G, Weierstall U, Williams GJ, Wunderer CB, Fromme P, Spence JC, Stehle T, Chapman HN, Betzel C, Duszenko M (2012) In vivo protein crystallization opens new routes in structural biology. Nat Methods 9 (3):259-262
Kozina V, Geist D, Kubinova L, Bilic E, Karnthaler HP, Waitz T, Janacek J, Chernyavskiy O, Krhen I, Jezek D (2011) Visualization of Reinke's crystals in normal and cryptorchid testis. Histochem Cell Biol 135:215-228

Kuznetsov AV, Troppmair J, Sucher R, Hermann M, Saks V, Margreiter R (2006) Mitochondrial subpopulations and heterogeneity revealed by confocal imaging: possible physiological role? Biochim Biophys Acta 1757:686-691

Lemasters JJ, Holmuhamedov E (2006) Voltage-dependent anion channel (VDAC) as mitochondrial governator-thinking outside the box. Biochim Biophys Acta 1762:181-190

Mesa H, Gilles S, Smith S, Dachel S, Larson W, Manivel JC (2015) The mystery of the vanishing Reinke crystals. Hum Pathol 46:600-606

Moura EF, Ventrella MC, Motoike SY (2010) Anatomy, histochemistry and ultrastructure of seed and somatic embryo of Acrocomia aculeata (Arecaceae). Sci Agric 67:399-407

Nagano T, Otsuki I (1971) Reinvestigation of the fine structure of Reinke's crystal in the human testicular interstitial cell. J Cell Biol 51:148-161

Nürnberger S, Klepal W, Vecsei V, Marlovits S (2006a) Ultrastructural insights into the world of cartilage-electron microscopy of articular cartilage. Osteosynth Trauma Care 14:168-180

Nürnberger S, Tichy B, Jagersberger T, Vécsei V, Marlovits S (2006b) Histological aspects of articular cartilage. Osteosynth Trauma Care 14:158-167

Nürnberger $\mathrm{S}$ et al (2013a) (Ultra-)structural details of cells and matrix during cartilage regeneration and differentiation in MACT-treated defects in the horse. J Tissue Sci Eng S2:p1-p10

Nürnberger S, Meyer C, Ponomarev I, Barnewitz D, Resinger C, Klepal W, Albrecht C, Marlovits S (2013b) Equine articular chondrocytes on ECM-scaffolds for cartilage defect treatment. Anat Histol Embryol 42:332-343

O’Gorman E, Fuchs KH, Tittmann P, Gross H, Wallimann T (1997) Crystalline mitochondrial inclusion bodies isolated from creatine depleted rat soleus muscle. J Cell Sci 110:1403-1411

Pabst MA, Rentenberger C, Bock E, Schmied R, Lackner M, Letofsky-Papst I, Wilhelm P, Crailsheim K, Karnthaler HP (2006) Protein crystals in the testes of the adult Apis mellifera at different ages. In: Proceedings of the 16th international microscopy Congress, $\mathrm{p} 534$

Pease D (1964) Histological techniques for electron microscopy. Academic Press, New York

Pena CE (1980) Periodic units in the intracristal and envelope spaces of neuronal mitochondria. An artifact due to delayed fixation. Acta Neuropathol 51:249-250

Pernas L, Scorrano L (2016) Mito-morphosis: mitochondrial fusion, fission, and cristae remodeling as key mediators of cellular function. Annu Rev Physiol 78:505-531

Pfanner N, Meijer M (1997) The Tom and Tim machine. Curr Biol 7:R100-R103

Ponomarev IV, Kochneva LM, Barnewitz D (2014) Effect of 3D chondrocyte culturing conditions on the formation of extracellular matrix in cartilage tissue-engineering constructs. Bull Exp Biol Med 156:548-555

Reinke F (1896) Beiträge zur Histologie des Menschen. I. Über Krystalloidbildungen in den interstitiellen Zellen des menschlichen Hodens. Arch Mikr Anat 47:34-44

Riopel M, Li J, Fellows GF, Goodyer CG, Wang R (2014) Ultrastructural and immunohistochemical analysis of the 8-20 week human fetal pancreas. Islets 6:e982949

Romeis B (1989) Mikroskopische Technik., 17 edn. Urban and Schwarzenberg, Munich 
Saito A, Fleischer S (1971) Intramitochondrial tubules in adrenal glands of rat. J Ultrastruct Res 35:642-649

Santos H (1966) The ultrastructure of the mucous granules from starfish tube feet. J Ultrastruct Res 16:259-268

Sawaya MR, Cascio D, Gingery M, Rodriguez J, Goldschmidt L, Colletier JP, Messerschmidt MM, Boutet S, Koglin JE, Williams GJ, Brewster AS, Nass K, Hattne J, Botha S, Doak RB, Shoeman RL, DePonte DP, Park HW, Federici BA, Sauter NK, Schlichting I, Eisenberg DS (2014) Protein crystal structure obtained at $2.9 \AA ̊$ resolution from injecting bacterial cells into an X-ray freeelectron laser beam. Proc Natl Acad Sci U S A 111:12769-12774

Schonherr R, Klinge M, Rudolph JM, Fita K, Rehders D, Lubber F, Schneegans S, Majoul IV, Duszenko M, Betzel C, BrandarizNunez A, Martinez-Costas J, Duden R, Redecke L (2015) Realtime investigation of dynamic protein crystallization in living cells. Struct Dyn 2:041712

Shiraki K, Neustein HB (1971) Intramitochondrial crystalloids and amorphous granules. Occurrence in experimental hepatic ischemia in dogs. Arch Pathol 91:32-40

Silvestro SR, Chapman GB (2004) A transmission electron microscope study of "New Dawn" climber rose (Rosa wichuraiana $\times$ safrano) exhibiting rose rosette disease. Plant Cell Rep 23:345-351

Spicer S, Lillie R (1961) Histochemical identification of basic proteins with Biebrich scarlet at alkaline pH. Stain Technol 6:365-370

Suganuma Y, Yamamoto H (1980) Occurrence, composition, and structure of mitochondrial crystals in a hypotrichous ciliate. $\mathrm{J}$ Ultrastruct Res 70:21-36

Swenson O, Grana L, Inouye T, Donnellan WL (1967) Immediate and long-term effects of acute hepatic ischemia. Arch Surg 95:451-463
Taira K (1979) Studies on intramitochondrial inclusions in the pancreatic acinar cells of the Japanese newt, Triturus pyrrogaster. I. Occurrence of intramitochondrial inclusions with long-term starvation. J Ultrastruct Res 67:89-94

Tandler B, Hoppel CL (1986) Studies on giant mitochondria. Ann N Y Acad Sci 488:65-81

Thamwiriyasati N, Sakdee S, Chuankhayan P, Katzenmeier G, Chen CJ, Angsuthanasombat C (2010) Crystallization and preliminary $\mathrm{X}$-ray crystallographic analysis of a full-length active form of the Cry4Ba toxin from Bacillus thuringiensis. Acta Crystallogr Sect F Struct Biol Cryst Commun 66:721-724

Tsutsui $\mathrm{H}$ et al (2015) A diffraction-quality protein crystal processed as an autophagic cargo. Mol Cell 58:186-193

Veenhuis M, Kiel JA, Van Der Klei IJ (2003) Peroxisome assembly in yeast. Microsc Res Tech 61:139-150

Voelz H (1968) Structural comparison between intramitochondrial and bacterial crystalloids. J Ultrastruct Res 25:29-36

Ward RT (1962) The origin of protein and fatty yolk in Rana pipiens. II. Electron microscopical and cytochemical observations of young and mature oocytes. J Cell Biol 14:309-341

Westrate LM, Drocco JA, Martin KR, Hlavacek WS, MacKeigan JP (2014) Mitochondrial morphological features are associated with fission and fusion events. PLoS ONE 9:e95265

Whittaker P (1995) Polarized light microscopy in biomedical research. Microsc Anal 44:15-17

Ponomarev I, Wilke I (2004) Manufacturing process for three-dimensional tissue structures und structures obtainable thereby, Google Patents 